\title{
Impact of the Low Sunspot Number to the Weather \& Climatic System Over Maritime Continent of Indonesia
}

Winarso AP*

State College Meteorology Climatology \& Geophysics, Indonesia

ISSN: 2637-8078

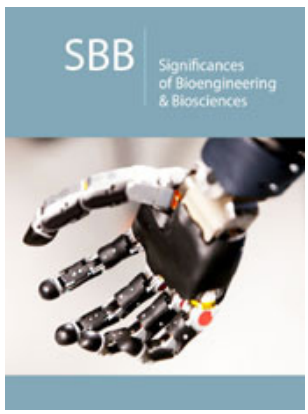

*Corresponding author: Winarso AP, State College Meteorology Climatology \& Geophysics, Indonesia

Submission: 泟 November 05, 2018

Published: 刻April 29, 2019

Volume 3 - Issue 2

How to cite this article: Winarso A. Impact of the Low Sunspot Number to the Weather \& Climatic System Over Maritime Continent of Indonesia.Significances Bioeng Biosci.3(2). SBB.000556.2019. DOI: 10.31031/SBB.2019.03.000556.

Copyright@ Winarso AP, This article is distributed under the terms of the Creative Commons Attribution 4.0 International License, which permits unrestricted use and redistribution provided that the original author and source are credited.

\section{Opinion}

As commented in the previous at the beginning of this year 2018, I found that there should be a relation with decreasing number of the sunspots in the current condition near the end of 2018. At Figure 1 below, it would like to present current data of the sunspots to be taken from Space Weather Prediction Center of the National Oceanic and Atmospheric Administration (https://www.swpc.noaa.gov/products/solar-cycle-progression, on October 12 $2^{\text {th }}, 2018$ ) with the last data in the several months in the mid-year with sunspot number to be less than 5 sunspots number/month. As is observed in the beginning of the year 2018 with sunspots number $5 /$ month to cause the extension of the winter season in the northern hemisphere of the north Indonesia Maritime Continent Area and around the end of the quarter I to previous quarter II 2018 somewhere around March-April 2018. Over both hemisphere surrounding of Maritime Continent of Indonesia area had developed 2 super Tropical cyclone that these super tropical generation were rather unusual development because they developed in the earlier development for the tropical season over the northern hemisphere and at the end of the period development of the tropical season over the southern hemisphere.

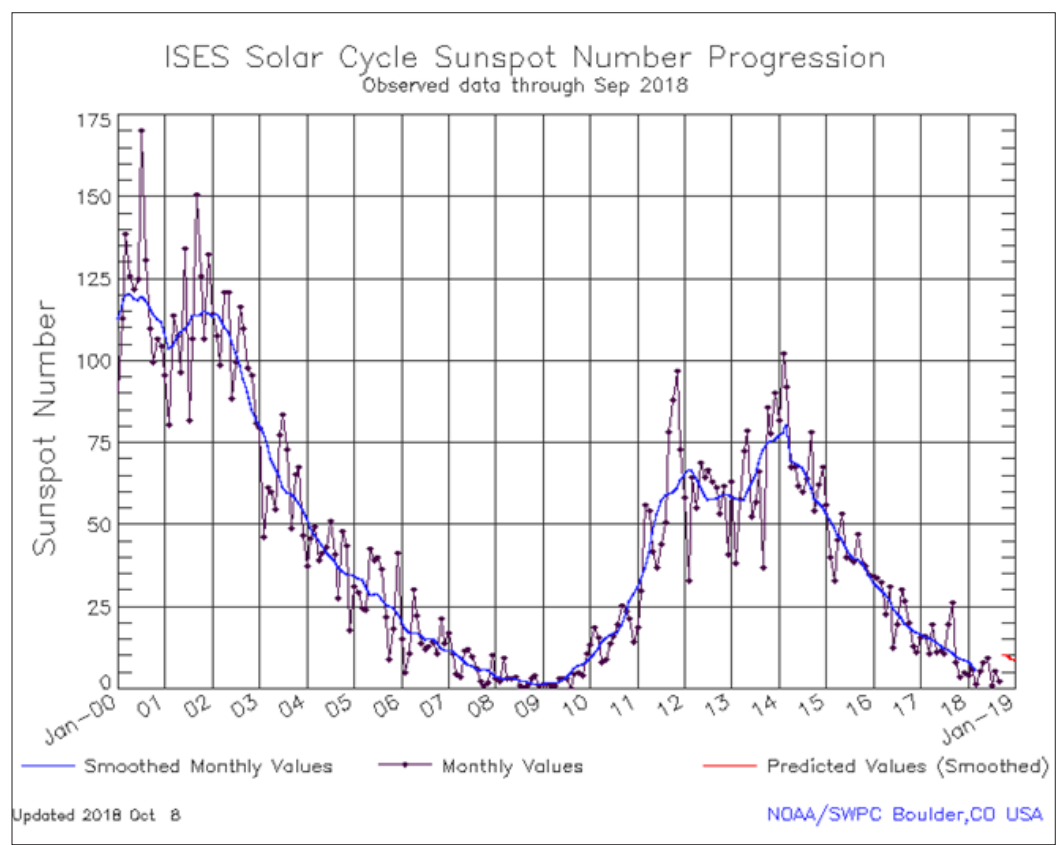

Figure 1: Current sunspots condition was taken off the mid-October 2018.

Impact for these condition over northern hemisphere would be the decreasing number of the tropical cyclone generation and over the southern hemisphere with decreasing in the sea surface temperature over most the waters in the western and eastern of Australia continent. The decreasing of the sea surface temperature over the wide area over western and eastern Australia may continue until the beginning last the end of 2018, wherein this period sun's 
declination just crosses the equator line [1]. An unusual condition from previous years that starting sun's declination crossing the equator, it would be followed with the transition period of the Australian monsoonal wind system from easterly up to westerly with mostly calm of the wind system. Unfortunately, during this period of mid-October 2018, the easterly-southeasterly wind system would some time be prevailed over southern of Indonesia Maritime Continent area and to be followed with strong wind and divergence wind over lower level. Such that cloudless condition is always active in the current condition until Sun's declination crossing the equator line un the end of September 2018. Opposite condition over small portion area such as over most central and northern Sumatera Island with the overcast condition and to be followed heavy rainfall occurrences in the few days. Where increasing number of the rainfall might encourage the disaster in terms of flash flood [2], flooding and landslide at the beginning of October 2018. But in reality starting August, September and few days until the middle of October 2018, over most of Indonesia not so much rainfall occurrences. In other words, the deficit of the rainfall might occur up to the middle of the October 2018. Where starting the end of September until current time in the mid of October 2018, there should be convective activities to produce the convective cloud. Unfortunately, this condition could not occur due to the certain reason especially cloudless convective cloud as the main part from convective process with surface heating to encourage unstable air and then upward of the moist parcel of the air in the lower atmosphere.

The lack of the lifted wet air parcel might cause less support of the convective cloud development such as current condition during September and current time until mid of October 2018 [3]. The cloud development over small portion in the northwestern area of Indonesia Maritime Continent area in beginning October, it was due to the surface heating over Indian Ocean west of Sumatera and the warm waters surrounding Northeastern of Sumatera Island and then they would be followed with lower level wind convergence to produce the convective development over central and northern Sumatera Island. From this point of view, it seems the warm waters would play important role in the cloud development as well as through convective/thermal and dynamical processes. Reversal pattern over southern areas especially Java up to Timor Islands with cooling waters and a little bit high surface pressure with supporting divergence lower wind, where surface high pressure is encouraged downward from upper air and divegence air in the lower level especially in the surface layer.

Based on the sea surface temperature report on the weekly basis from various National Meteorological from first week up to the second week October 2018, it seems a little bit changing of the Sea Surface Temperature over Southern Waters of Indonesia Maritime Continent. Where reducing of the area below normal of the weekly anomaly of the Sea Surface Temperature over Southern waters of Indonesia Maritime Continent. It seems that coincide Sun's declination southward displacement to affect slow response of the warming to the surface waters, especially in this area. Further investigation for the slow response of the warming to the Southern Indonesia Maritime Continent waters could come from the certain aspect. This certain aspect would be from the heating source of the Sun's activities. Based upon the previous investigation from the global perspective such as El Nino episodes, where during Sun's cycles having maximum more than 150 sunspots/month in cycles no. 20, 21, 22 and 23 with more frequent of the warming episode of El Nino [3]. But current cycle with maximum to be less than 100 sunspots with frequent occurrences of the cooling episode of the La Nina. With the current condition of the sunspots would be less than 5 or toward minimum activity of the Sun's activity, it seems the less support to the heating to occur in the current condition. Such that Sea Surface Temperature over Southern waters of Indonesia Maritime Continent area would be the slower heating process. Until the middle of the October 2018 over southern Indonesia Maritime Continent would be slow cloud development and to be less of the rainfall. In other words, weather and climate would be dry and with mostly calm wind over most of the Southern Indonesia Maritime Continent area.

\section{References}

1. http://www.bom.gov.au.

2. http://www.bmkg.go.id.

3. https://www.swpc.noaa.gov/products/solar-cycle-progression. 